\title{
(2BiblioCanto)
}

\section{ZILA MAMEDE, POETICAMENTE BIBLIOTECÁRIA ÍCONE NO RIO GRANDE DO NORTE}

Rejane Lordão Monteiro

Resumo: Faz reflexão sobre a importância de Zila Mamede, paraibana de Nova Palmeira, que segundo sua declaração, foi transplantada para o Rio Grande do Norte. A sua importância é visível na área da biblioteconomia do Estado, através dos seus projetos direcionados para bibliotecas, das suas pesquisas, dos seus poemas em livros e da sua identidade profissional, reconhecida nacionalmente. Trata-se de um texto memorialístico.

Palavras- chave: Zila Mamede. Biblioteconomia. Memória.

\section{INTRODUÇÃO}

Para compreender a importância de Zila Mamede ${ }^{2}$ é preciso refletir sobre a sua trajetória e pioneirismo como bibliotecária, no Estado do Rio Grande do Norte e o quão era respeitada em âmbito nacional.

Que sorte ela adotar o Rio Grande do Norte, como sua terra de coração! Sobre isso foi enfática em roda de conversas com Carlos Lira (Diretor da TV Universitária), Alvamar Furtado e Celso da Silveira, em 03 de fevereiro de 1981, no Programa Memória Viva, da TV Universitária da Universidade Federal do Rio Grande do Norte (UFRN) (ZILA MAMEDE, 1981).

[Nova Palmeira] é o chão onde nasci, e eu gostaria que ela fosse no Rio Grande do Norte, porque me sinto tão norte-rio-grandense, que tenho susto quando olho a minha carteira de identidade. Nisso não há nenhum preconceito contra a Paraíba. Apenas fui transplantada muito pequena, a tempo de me sentir enraizada no Rio Grande do Norte. Daí porque eu digo que gostaria que Nova Palmeira, a vila fundada pelo meu avô e pelo meu padrinho de batismo, fosse no Rio Grande do Norte. Era uma fazenda, uma

\footnotetext{
${ }^{1}$ Graduada em Biblioteconomia e Documentação - UFPB; Graduada em Ciências Sociais - UFRN; Graduada em Jornalismo e Comunicação Social - UFRN. Lattes: http://lattes.cnpq.br/3637200485480642

${ }^{2}$ Zila da Costa Mamede, bibliotecária, poetisa, escritora, nasceu em Nova Palmeira/PB, em 15 de setembro de 1928 e morreu em Natal/RN, em 13 de dezembro de 1985.
} 


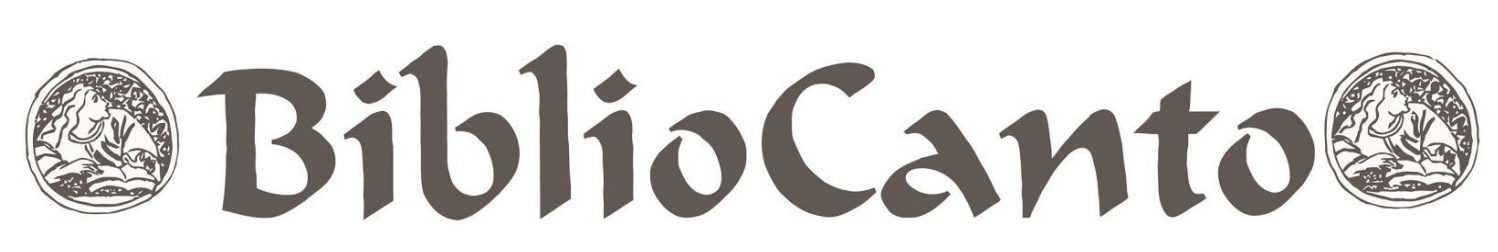

(ZILA MAMEDE, 1981).

vila, hoje é mais um município brasileiro, mas não é como município, e sim, como sítio do meu avô que permanece na minha geografia sentimental.

Mas sempre manteve seu olhar saudoso e atencioso para sua terra materna.

No livro 0 Arado, prefaciado por Luís da Câmara Cascudo3: Todos os poemas nasceram no chão sagrado, com chuva do Céu e suor dos rostos vigilantes, surgidos na inspiração provocadora de uma inegável vivência emocional.

Olhando para o passado, retrata em textos poéticos as lembranças da sua meninice, em família, na sua terra natal.

Em 29 de abril de 1971, escreveu para Maria Alice Barroso ${ }^{4}$ (bibliotecária, à época Diretora do Instituto Nacional do Livro):

\begin{abstract}
Eis aí um pedido "pessoal" meu. Dê uma biblioteca a essa gente. [...] nessa última seca o lugar onde nasci não oferecia senão miséria e desolação a todos. Mas o nível de inteligência e o desejo de aprender, e o dom artístico e literário que há em todos os seus habitantes é uma coisa de espantar. [...] assumo a responsabilidade do funcionamento, instruindo, mesmo por carta, a minha afilhada. Estou mandando por ela uma série de livros de minha biblioteca particular e um manual de biblioteconomia muito elementar para que ela possa se orientar no mínimo pra a instalação da sala. Você não estaria apenas prestando um serviço público, estaria DANDO UMA GRANDE ESMOLA CULTURAL a um punhado de gente que vive porque DEUS ainda continua sendo barra limpa, apesar de tudo. (MAMEDE; BARROSO, 1971).
\end{abstract}

Havia uma camaradagem profissional entre ambas. Tanto que Zila escreveu o artigo: Os vários caminhos de Maria Alice Barroso: cronologia literária, publicado no Suplemento Literário, Belo Horizonte, Imprensa Oficial, 09 mar., 1974.

Antes de ser bibliotecária, segundo a Cronologia Zila Mamede: 1928-1985, organizada por Gildete Moura de Figueirêdo:

[...] Fez o Curso Básico de Contabilidade, no Colégio Imaculada Conceição (1941);

Auxiliar de Escritório do Curso Comercial Básico na Escola Técnica de Comércio "Imaculada Conceição", Natal. (1946);

Técnico em Contabilidade na Escola Técnica de Comércio "Imaculada Conceição", Natal. (1949);

\footnotetext{
${ }^{3}$ Luís da Câmara Cascudo, historiador, antropólogo, nasceu em Natal/RN, em 30 de dezembro de 1889 e morreu em Natal/RN, em 30 de julho de 1986.

${ }^{4}$ Maria Alice Giudice Barroso Soares, bibliotecária, escritora, nasceu no Rio de Janeiro/RJ em 1926 e morreu em Juiz de Fora/MG, 12 de outubro de 2012.
} 


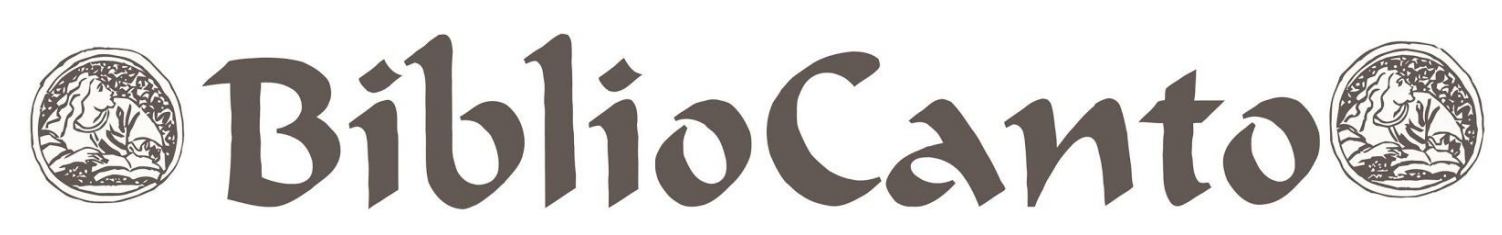

Foi aprovada no vestibular do Curso de Direito da Universidade Federal do Rio Grande do Norte (1955) (FIGUEIRÊDO; GALVÃO, 2005).

Optou por Biblioteconomia, diplomando-se em 15 de dezembro de 1956, pela Biblioteca Nacional do Rio de Janeiro.

Em 1957, registrou-se como jornalista profissional na Associação Norte-rio-grandense de Imprensa; foi redatora para jornais e revistas: Diário de Pernambuco, A República, Diário de Natal, O Globo, O Tempo, Correio da Manhã, Diário de Notícias, Jornal de Letra, Revista de Cultura Brasileira (editada na Espanha pela Embaixada do Brasil em Madri).

Ainda neste ano, exerceu o cargo de Bibliotecária do Instituto de Educação do Rio Grande do Norte (rebatizado Atheneu Norte-Riograndense) e da Sociedade Cultural do Brasil - Estados Unidos - SCBEU; escola de língua inglesa.

Extremamente versátil, onde existia biblioteca no Estado do Rio Grande do Norte, havia a sua digital.

Empenhou-se em mudar o cenário de carência, ineficiência e de falta dessas instituições no Estado, quiçá, com a mesma visão de Briquet de Lemos:

[...] numa sociedade onde cultura em geral é algo marginal, [...]. As bibliotecas tendem a ser marginais e outras instituições culturais, os museus são marginais, os arquivos são esquecidos, são comidos pelos ratos, cupins etc. (LEMOS, 2013).

Em 1959, na Chefia do Serviço Central de Bibliotecas (SCB) da UFRN, (instalado no prédio da Reitoria, na Av. Hermes da Fonseca, 780, Natal, período: 1959-1974); como forma de minimizar a falta de recursos humanos e de realizar uma aquisição racional e eficiente, sabiamente, estruturou o setor para coordenar as atividades de aquisição do material bibliográfico, destinados às Bibliotecas (localizadas nas Faculdades, em instalações distantes da Reitoria).

Também realizou trabalho técnico na Biblioteca do Tribunal de Justiça do Rio Grande do Norte.

Participou da implantação da Biblioteca Pública Estadual Câmara Cascudo e foi sua coordenadora no período, 1969-1972. Tornou-a partícipe do Instituto Nacional do Livro, observando que ele tinha a meta de apoiar e implantar bibliotecas 


\section{(2BiblioCanto)}

públicas em todo o Brasil. Posteriormente, este Instituto foi substituído pelo Sistema Nacional de Bibliotecas Públicas que passou a ser integrado à Fundação Biblioteca Nacional.

No ano de 1971, abalizada por sua competência, foi cogitada para dirigir a Biblioteca Nacional, mas declinou, por fidelidade e responsabilidade com a Universidade Federal do Rio Grande do Norte.

[...] não posso sair de Natal, agora, pois como deixaria a Universidade sem ninguém, se uma das outras duas bibliotecárias teve bebê agora e a outra não tem tempo integral? Se estou atenta com a mudança de governo, na defesa da Biblioteca Pública, etc.? Não estou dando uma de heroína, deus me livre. Este ano é um ano difícil, de mudança em tudo, de transição administrativa. Como eu sei que sou bem aceita em todos os meios, no momento não é político que eu saia daqui, pelo menos enquanto Dr. Onofre Lopes estiver na Reitoria. Ele ficou muito feliz com o resultado do curso que dei em S. Luís, com o of. que recebeu do Reitor de lá e muito "babativo" com sua carta convidando para (imagine, meu Deus, com que cara?) dirigir a Biblioteca Nacional [...]. Olhe, levo tudo isso na brincadeira, mas no fundo, no fundo fiquei tanto surpresa quanto emocionada com o pré-convite-sondagem. Fiquei mesmo [...] (MAMEDE; BARROSO, 1971).

Atuou como Assessora Técnica no Instituto Nacional do Livro, em Brasília, pelo período 1972-74.

Em termos de conteúdo, não se limitou à necessidade de inovar e de afirmar a sua identidade nacional, preocupou-se em formar e qualificar pessoas visando à sobrevida e dinâmica das bibliotecas de Natal/RN.

Em 1964, encaminhou para cursar biblioteconomia: Sônia Campos Ferreira para a Universidade Federal da Bahia; Norma Leite Rodrigues e Safira Tavares para a Biblioteca Nacional, Rio de Janeiro.

Na Biblioteca Pública do Estado do Rio Grande do Norte, em 1969, viabilizou a ida de Ana Zélia de Mello Maia para o Curso de Especialização em Documentação Científica do Instituto Brasileiro de Bibliografia e Documentação (IBBD).

Ainda na UFRN, em 1971, encaminhou Gildete Moura de Figueirêdo para o Curso de Biblioteconomia e Documentação da Fundação Universidade do Maranhão. 


\section{(2) BiblioCanto)}

Com a Reforma do Ensino Superior (1974) houve a implantação do Campus Universitário, significando a centralização administrativa e acadêmica da UFRN e a adequação das bibliotecas.

A nova estrutura oficializou a Biblioteca Central, Órgão Suplementar, representando o somatório das antigas bibliotecas e a fusão de coleções díspares.

A dinâmica de funcionalidade dessa nova e grande estrutura significou um desafio, tendo em vista o pequeno quadro de bibliotecários e de auxiliares, dispunha de apenas sete bibliotecários.

Para solucionar a falta de auxiliares, contou com alunos dos cursos da própria Universidade, contratados através do Programa Bolsa de Trabalho.

Quanto à solução para ampliação do quadro de bibliotecários, fez estudo de possibilidades viáveis e céleres.

A existência do Curso de Biblioteconomia do Centro de Ciências Sociais Aplicadas da Universidade Federal da Paraíba despertou interesse, por atender os requisitos, principalmente o de racionalidade.

Primeiro, em 1975, encaminhou Rejane Lordão Monteiro para o Curso de Biblioteconomia da Universidade Federal da Paraíba, foi o primeiro passo para um programa mais audacioso.

Fez diligências e propôs um projeto global para a formação de bibliotecários para a Universidade Federal do Rio Grande do Norte, que resultou na formalização do Convênio n. 36/76, assinado em 08 de janeiro de 1976, pelo Reitor Domingos Gomes de Lima/UFRN e por Orlando Cavalcante Gomes, Vice-Reitor em exercício/UFPB. Com duração prevista para quatro anos, objetivava a formação de 15 bibliotecários.

Foi designada executora, sendo substituída por Sônia Campos Ferreira.

Os candidatos eram naturalmente selecionados entre funcionários e bolsistas da Biblioteca Central, observadas suas habilidades, aptidão e interesse, no desenvolvimento das atividades, próprias de biblioteca, sob a supervisão de bibliotecários. As exceções recaíram para alunos de cursos da área humanística da Universidade:

1976 - Primeiro semestre: 


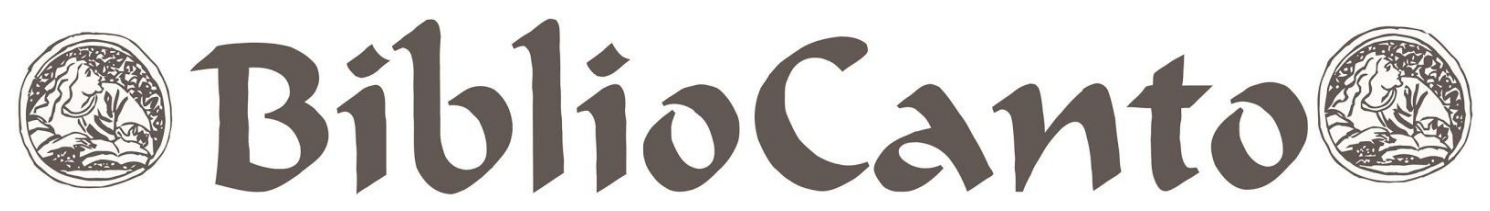

Liana Maria Santos Nobre

Lígia Xavier de Araújo

Maria Goretti Silva Maux

Maria da Salete Bezerra

Terezinha de Jesus Silva

1976 - Segundo semestre:

Ângela de Oliveira Dieb

Terezinha Anibas da Cunha

1977 - Primeiro semestre:

Antonia de Freiras Neta

Evânia Leiros de Souza

Francisca de Assis de Souza

Neuza Pinheiro de Medeiros

Renata Passos Filgueira de Carvalho

1977 - Segundo semestre:

Maria do Socorro Borba

1978

Rildeci Medeiros

Com a retomada do Convênio

1989

Margareth de Lara Menezes

Maria da Saudade Guimarães

Marilene Bezerra

Moema Diana Mamede

Olga Maria dos Santos (desistiu)

1990

João Bosco Medeiros

Ricardo Guimarães

Multifacetada; escrevia, realizava, pesquisava, gerenciava, viajava a convite ou a trabalho; trabalhava muito, seu tempo diário parecia interminável. 


\title{
(2BiblioCanto?
}

Publicou em coautoria com Veríssimo de Melo $^{5}$, Xico Santeiro ${ }^{6}$ : pequena bibliografia anotada, na Rev. do Instituto de Antropologia, jul. 1966. Como Separata.

Realizou exaustivo levantamento bibliográfico acerca do folclorista natalense, Luís da Câmara Cascudo. ${ }^{7}$

Em 11 de março de 1968, escreveu para Luís da Câmara Cascudo, [certamente, estava em Recife, em trabalho no Centro de Informação e Documentação Técnico-Científica para o Nordeste da SUDENE]:

\begin{abstract}
Cascudo, menino: [...] Pois olhe, eu nem acredito que esteja em vias de terminar um negócio que se chama : LUIS DA CÂMARA CASCUDO: QUARENTA E SETE ANOS DE VIDA INTELECTUAL, 1918-1965). Pois olhe, meu caro Mestre, tenho em frente ao meu nariz CINCO CADERNOS datilografados contando com exatamente OITOCENTAS PÁGINAS DE TEXTO. [...] Neguinho, será que você me mandaria isso DEPRESSINHA,? Eu te daria milhões de cheiros (com Licença de minha Madrinha D. Dália) se me fazes tão grande favor. Não sei quando vou a Natal. Mas estou todinha em Natal, pois dia e noite noite e dia estou entre LUíS DA CÂMARA CASCUDO e sua bibliografia deste tamanho (CASCUDO; MAMEDE, 1968).
\end{abstract}

Tudo manualmente organizado, em sua máquina portátil de datilografia. Foram, pelo menos, cinco anos, entre a fase de coleta de dados e finalização do trabalho.

A pesquisa foi iniciada em 1964, objetivando sua dissertação de Mestrado na Universidade de Brasília. Só frequentou o curso por dois anos (1964-1965), por motivos superiores não concluiu.

Deu prosseguimento ao trabalho e a obra foi publicada com o título: Luís da Câmara Cascudo: 50 anos de vida intelectual, 1918-1968: bibliografia anotada, pela Fundação José Augusto (FJA), Natal/RN. 1970. 2 volumes, 3 Tomos (v.1, parte 1-2, e v.2,).

Em 1976, iniciou o trabalho de pesquisa bibliográfica sobre o poeta pernambucano, João Cabral de Melo Neto. ${ }^{8}$

\footnotetext{
${ }^{5}$ Veríssimo de Melo, folclorista, escritor, nasceu em Natal/RN, em 09 de julho de 1921 e morreu em Natal/RN, em 18 de agosto de 1996.

${ }^{6}$ Xico Santeiro, pseud. de Joaquim Manoel de Oliveira, escultor, nasceu em Tinguijada, Santo Antonio do Salto da Onça/RN, em 1898 e morreu em 1966.

${ }^{7}$ Luís da Câmara Cascudo, historiador, antropólogo, nasceu em Natal/RN, em 30 de dezembro de 1889 e morreu em Natal/RN, em 30 de julho de 1986.

${ }^{8}$ O poeta João Cabral de Melo Neto nasceu em Recife/PE, em 09 de janeiro de 1920 e morreu no Rio de Janeiro/RJ, em 09 de outubro de 1999.
} 


\section{(2) BiblioCanto)}

O próprio poeta (João Cabral) Ihe enviou o seu arquivo, com cerca de doze a quinze pastas de documentos: recortes e artigos de jornal e revistas, capítulos de livros, entrevistas, fotografias, todas as suas obras e endereços de críticos de diversos países que haviam escrito sobre a sua obra.

Não foi tarefa fácil trocar correspondências, organizar o material com as informações recebidas, fazer leitura detalhada, fichar os dados bibliográficos, sistemicamente organizados, em tópicos de identificação.

Contou com o apoio, sugestões e a disponibilidade do acervo da biblioteca particular (Brooklin, São Paulo) de José Mindlin.

O trabalho se estendeu após sua aposentadoria. Durou quase uma década.

Em 1983-84, realizou a revisão dos Índices (em seu escritório no apartamento), auxiliada pelas bibliotecárias: Gildete Moura de Figueirêdo e Rejane Lordão Monteiro, (trabalho que ela fez questão em remunerar).

Era a época da telenovela Guerra dos sexos, que ela assistia assiduamente, no horário do seu jantar, às $19 \mathrm{~h}$, era fã de Paulo Autran ${ }^{10}$ e Fernanda Montenegro ${ }^{11}$.

Comentário à parte, na intimidade, era uma boa dona de casa, conduzia as tarefas de casa e era quem realizava as compras de consumo diário.

A publicação ocorreu em 1987, (após a sua morte), com o título: Civil geometria: bibliografia crítica, analítica e anotada de João Cabral de Melo Neto, 1942-1982.

Tudo foi feito em acordo com o que estava previamente definido: o título (escolhido por ela e João Cabral), a introdução rascunhada.

Tecnicamente tudo foi revisado pelas bibliotecárias Gildete Moura de Figueirêdo e Rejane Lordão Monteiro.

Havia uma espécie de diário com as instruções do que deveria ser feito com o material bibliográfico após a publicação da obra:

\footnotetext{
9 O empresário, escritor e bibliófilo José Ephim Mindlin nasceram em São Paulo/SP, em 08 de setembro de 1914 e morreu em São Paulo/SP, em 28 de fevereiro de 2010. Possuía um acervo de sessenta mil volumes entre livros, periódicos, documentos e manuscritos. Em 2006, resolveu doar todo o seu acervo para a Universidade de São Paulo.

${ }^{10}$ Paulo Paquet Autran, ator, nasceu no Rio de Janeiro/RJ em 07 de setembro de 1922 e morreu em São Paulo/SP, em 12 de outubro de 2007.

${ }^{11}$ Fernanda Montenegro pseud. de Arlette Pinheiro Esteves da Silva Torres, atriz, nasceu no Rio de Janeiro/RJ, em 16 de outubro de 1929.
} 


\section{(2) BiblioCanto?}

1. O trabalho deve ser entregue sob documento de co-autoria à bibliotecária Cremilda Perucci, da Universidade Federal de Pernambuco. Ela tem conhecimento e concorda com a minha decisão e já decidimos isso desde 1977, confirmamos em abril de 1880, no Recife. É impossível que eu e Cremilda morramos ao mesmo tempo. Mas, caso isso aconteça, o que será patético, entregar o trabalho ao INSTITUTO JOAQUIM NABUCO DE PESQUISAS SOCIAIS. Espero não morrer, pelo menos até conversar sobre o assunto, com meu amigo Fernando Freire.

2. Todo o material bibliográfico dos 15 álbuns pertence a João Cabral de Melo Neto e sua família e a eles deve ser devolvido sob recibo. Espero concluir o fichamento antes de poder o morrer ou ter que morrer.

3. Todo o material bibliográfico do qual não disponha a biblioteca particular de João Cabral de Melo Neto, deve ser entregue a Stella Maria Cabral de Melo, para completar a coleção.

4. Tudo o que for duplicata para biblioteca particular de João Cabral, deve ser entregue a José Mindlin. Ele também já está ciente disso.

5. Toda a minha correspondência deve ser entregue por doação a José Mindlin. Ele já sabe o que fazer com a correspondência. Natal, 2 de janeiro de 1981 (SOBRAL, 2016).

Com características modernistas, em 11 de outubro de 1978, incentivando a agregação da classe, participou da Assembleia de Criação da Associação Profissional dos Bibliotecários do Rio Grande do Norte (APBERN), sendo eleita membro do Conselho Fiscal.

Participou como conselheira, do planejamento de criação do Curso de Biblioteconomia na UFRN (criado em 04 de junho de 1990, através da Resolução N64/90-CONSEPE).

A sua identidade profissional, tornava-a naturalmente, madrinha da ideia, especialmente porque, os docentes eram oriundos do seu esforço em qualificá-los, através do Convênio UFRN e UFPB.

Antonia de Freiras Neta

Evânia Leiros de Souza

Francisca de Assis de Souza

Liana Maria Santos Nobre

Maria Goretti Silva Maux

Maria da Salete Bezerra

Maria do Socorro Borba

Neuza Pinheiro de Medeiros 


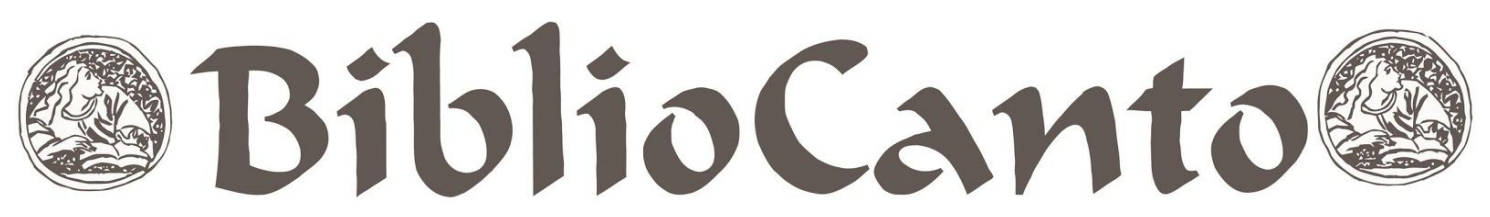

Renata Passos Filgueira de Carvalho

Rildeci Medeiros

Terezinha Anibas da Cunha

Decerto, havia adiado este projeto, até que percebesse que o quadro de docentes assegurava a dinâmica do curso. Antes, observou que era impossível estimular a UFRN, no sentido de criar um curso de Biblioteconomia, consciente que estaria lutando por mais uma escola carente, no Brasil.

Sob denominação de Departamento de Biblioteconomia (DEBIB). Sua instalação se deu na Biblioteca Central Zila Mamede (BCZM), em 29 de outubro de 1992, com aporte financeiro do Centro de Ciências Sociais Aplicadas (CCSA), centro ao qual se integra. O objetivo inicial era o de estruturar e criar o Curso de Graduação em Biblioteconomia no âmbito da universidade, o que aconteceu seis anos mais tarde (DEPARTAMENTO DE CIENCIA DA INFORMAÇÃO, [201-]).

Poeticamente escreveu e foram publicados:

Rosa de pedra (1953)

Salinas (1958)

O Arado (1959)

Exercício da palavra (1975)

Corpo a corpo (1978)

Navegos (1978)

A Herança (1984)

Com dicção exuberante, postura ética, sem vaidade com suas criações, respondeu quando o assunto foi sobre sua inspiração para escrever: "[...] nunca tive pretensão pra literatura [...] até porque, no colégio era proibido pensar em literatura, romance era pecado, poesia era escolhida pra gente ler [...]". (ZILA MAMEDE, 1981).

Carlos Drummond de Andrade ${ }^{12}$ era o seu amigo mentor, palpitava sobre a sua atividade poética.

12 O poeta Carlos Drummond de Andrade nasceu em Itabira/MG, em 31 de outubro de 1902 e morreu no Rio de Janeiro/RJ, em 17 de agosto de 1987.

BiblioCanto, Natal, v. 5, n.1, p. 105 - 117, 2019. 


\section{(2BiblioCanto)}

A amizade começou após ela enviar para ele, um exemplar do seu primeiro livro, Rosa de Pedra (1953).

Outro poeta, seu amigo dileto foi Manuel Bandeira ${ }^{13}$ :

[...] Tivemos logo, assim, uma simpatia muito grande um pelo outro, e passei a ser a neta que ele não teve. Eu ia toda semana a casa dele; antes de ir para a Academia ele fazia sorvete pra mim, sorvete de café. Nas férias, eu levava castanha de caju, aquelas cobertas de açúcar para ele dar a uma grande amiga dele, Madame Blanche. Ele, realmente, era um pai pra mim. Ele me dava todas as duplicatas de livros que recebia; entrada para todas as estreias de teatro e balé do Rio de Janeiro. Ele, realmente, me tratou como uma pessoa da família e fez mais: obrigou-me a estudar. Inclusive, em cartas dele para mim, ele me obrigava a estudar latim, a conhecer os clássicos, 'se eu não tivesse coragem de estudar latim, que pegasse essas traduções lineares, chamadas 'tradução de burro', e lesse o latim e a tradução justalinear, página dupla, latim e português, que eu 'tinha a obrigação de aprender os clássicos: sem ler, ninguém era poeta! (ZILA MAMEDE, 1981).

Partiu da vida, o mar em manifesta soberba abraçou o seu corpo, tornado-a imortal pelo seu legado.

No Brasil o mérito é pouco reconhecido, por vezes pequenos feitos são qualificados, uma amostra disto, está na reflexão do bibliotecário Briquet de Lemos sobre o patrono dos bibliotecários brasileiros:

[...] Bastos Tigre não foi levado à condição de patrono da Biblioteconomia e dos bibliotecários pelo seu fazer profissional, por aquilo que ele teria feito como um bibliotecário [...]. Ele se dedicava mais ao teatro de revista e a publicidade. Pela Biblioteconomia a única qualificação que the é atribuída é o fato de ter sido o primeiro bibliotecário aprovado em um concurso no Brasil. (LEMOS, 2013).

Bibliotecários que guardam Zila na memória afetiva consideram-na patrona da biblioteconomia e dos bibliotecários do Rio Grande do Norte; possivelmente um ato formal de reconhecimento, talvez, por iniciativa do Conselho Estadual de Cultura do $\mathrm{RN}$, seria oportuno e justo.

Como não admirá-la?

Como não agradecer por tudo que foi, fez, escreveu, ensinou?

${ }^{13}$ O poeta Manuel Carneiro de Souza Bandeira nasceu em Recife/PE, em 19 de abril de 1886 e morreu no Rio de Janeiro/RJ, em 13 de outubro de 1968. 
